ARCHIVO ESPAÑOL DE ARTE, LXXXV, 338

ABRIL-JUNIO 2012, pp. 125-146

ISSN: 0004-0428

\title{
LA VIRGEN CON EL NIÑO Y LAS ALMAS DEL PURGATORIO DE PEDRO MACHUCA Y SU VINCULACIÓN ITALIANA
}

\author{
ANa Ávila \\ Universidad Autónoma de Madrid
}

Se estudia el ingreso del cuadro en el Museo del Prado en 1935 -lo cual motiva el estado de la cuestión del artista en esos momentos y la consolidación de su imagen como pintor- y su probable procedencia napolitana, resaltando la idiosincrasia italiana de su iconografía, común en el Virreinato.

Palabras clave: Pintura; Renacimiento; Machuca; Iconografía; Madonna delle Grazie; Museo del Prado.

\section{PEDRO MACHUCA'S VIRGIN AND CHILD APPEARING TO THE SOULS IN PURGATORY AND ITS ITALIAN CONNECTIONS}

The author examines the incorporation of this painting into the collections of the Prado Museum in 1935, which generated the scrutiny of the state of knowledge concerning the painter at the time and the consolidation of his artistic reputation. The painting probably came from Naples, thereby explaining the idiosyncratic Italian iconography, common in the Viceroyalty.

Key words: Painting; Renaissance; Machuca; Iconography; Our Lady of Grace; Prado Museum.

\section{De Italia al Museo del Prado}

No fue hasta 1935 cuando las colecciones públicas españolas contaron con una obra de Machuca (fig. 1). En el momento en que el cuadro, motivo del presente artículo, ingresó en el Museo del Prado este artista en su condición de pintor era prácticamente desconocido. Ha sido Ceán Bermúdez en 1800 el primero en consolidar cierta imagen personal y artística al recopilar las fuentes literarias que le precedían ${ }^{1}$, desde Lázaro de Velasco (¿1550-1565?) a Palomino (1715) pasando por Francisco de Holanda (h. 1548), Juan Alonso Butrón (1626) y Lázaro Díaz del Valle (1656-1658). En casi todas se recoge su doble actividad, arquitecto y pintor, siendo de destacar que el artista y teórico lisboeta le menciona exclusivamente en el campo de la pintura, manifestación en que de todos ellos recibe elogios sin que se especifique obra concreta. En estas

\footnotetext{
1 CeÁn Bermúdez, 1965 (1800), III: 58-59.
} 


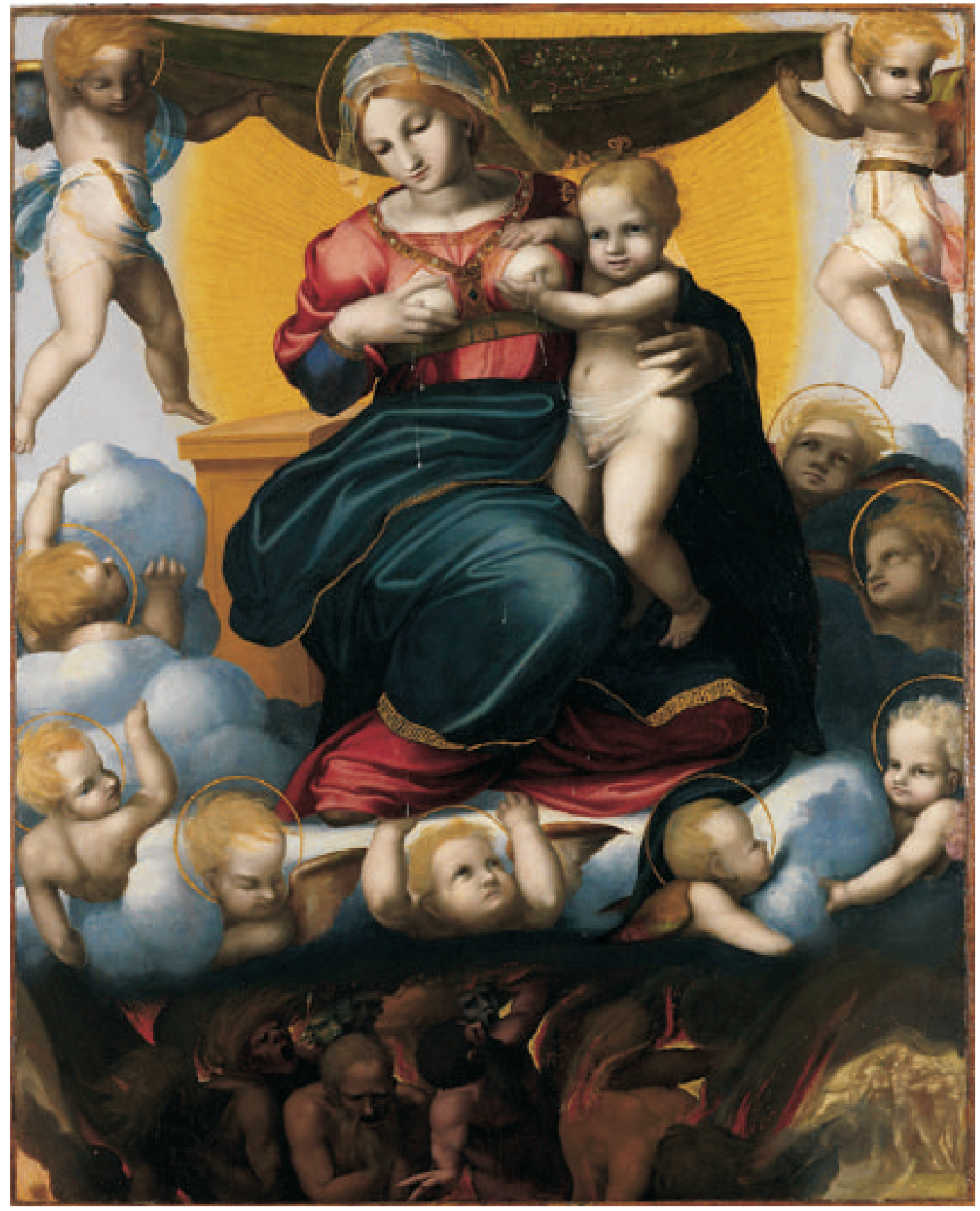

Fig. 1. Pedro Machuca. La Virgen con el Niño y las almas del purgatorio. Madrid, Museo del Prado (Foto museo). 
fuentes históricas Machuca, como identidad personal y artística, se descubre tras una estancia en Italia donde estaría vinculado con el lenguaje de importantes figuras como Miguel Ángel y Rafael. El reino de Granada, donde hizo "grandes obras de pintura", y las localidades de Jaén, Toledo y Uclés, en las que también "pintó maravillosas obras", son los espacios para la acción de esta "águila" del Renacimiento español.

A principios del siglo XIX la imagen de Machuca pintor se deja de lado frente a la de arquitecto activo en Granada ${ }^{2}$. A finales de la centuria se le situaba en el ámbito de la ciudad nazarí como un pintor de escasa producción documentada y de quien no se conservaba obra e incluso se le atribuía alguna con impronta italiana dadas las referencias literarias antes mencionadas ${ }^{3}$. En su Dictionnaire critique et documentaire des peintres, sculpteurs, dessinateurs et graveurs (1911-[1924]) Bénézit precisa que la mayoría de las obras de este artista ha desaparecido por lo que no se puede tener conocimiento de causa para juzgarle ${ }^{4}$ Las Fuentes Literarias para la Historia del Arte Español (1923), de Sánchez Cantón, le tratan de "pintor notable", pero "casi desconocido" recogiéndose exclusivamente el retablo de San Pedro de Osma de la catedral de Jaén ${ }^{5}$. Es la primera vez que se asocia una obra de arte conservada con la figura de Machuca como pintor, con la cual, por otra parte, se le relacionará documentalmente (1546). Por estas fechas, Gómez-Moreno cuestiona su categoría en el terreno de la pintura y las alabanzas que le dirige la tradición histórica: en cuanto pintor es, indica, una figura "que se diluye" mientras toma resonancia su actividad de arquitecto ${ }^{6}$. Tal es así que llega a situar a Jacopo Florentino por encima de Machuca en consideración artística a propósito de dilucidar la autoría de las tablas del retablo de la Santa Cruz de la Capilla Real (1521).

La aparición en escena en 1935 del cuadro representando La Virgen con el Niño y las ánimas del purgatorio reforzó la titubeante personalidad pictórica de Machuca, materializó las referencias literarias que le vinculaban a la cultura italiana y reforzó elocuentemente su identidad como español. Cuando en 1942 la obra se recoge en el catálogo del Museo del Prado se dice que "fue adquirida en Italia en 1935 con cargo a la subvención del Estado"7. Como tal ha ido apareciendo en los diferentes catálogos mientras que la guía de El Greco y la pintura española del Renacimiento de 2001 le atribuye el origen de Spoleto (Perugia) ${ }^{8}$. Es esta la procedencia que se viene mencionando desde que Gómez-Moreno describiera el cuadro unos pocos años después de su ingreso en el museo. El término adquirido ${ }^{9}$ se ha venido simultaneando con el de encontrado, hallado y aparecido ${ }^{10}$, ahondando en una situación de sorpresa y estima la constatación física de una obra pictórica de Machuca, además en Italia, provista de datos que se consideraron reveladores sobre su identidad.

Efectivamente, La Virgen con el Niño y las ánimas del purgatorio estaba en Spoleto cuando se tramitó su compra, localidad en donde fue vista por Enrique Pérez Comendador, quien ejerció de intermediario entre el representante del propietario y el Museo del Prado ${ }^{11}$. Este escultor es-

\footnotetext{
2 Llaguno y Amírola, 1829: 221-222.

3 Gómez-Moreno, 1892.

${ }^{4}$ BÉNÉZIT, 3: 165.

5 SÁNCHeZ CANTÓN, I: 117, n. 2.

6 GómeZ-Moreno, 1925, I: 277-278.

${ }^{7}$ Museo del Prado. Catálogo de los cuadros, 1942: 347, n. ${ }^{\circ} 2579$. Una etiqueta pegada en el reverso del cuadro indica "Museo del Prado/ Num. Machuca/Entrada: 1935/...".

${ }^{8}$ Museo del Prado. El Greco y la pintura española del Renacimiento, 2001: 38. La misma noticia en JAVIER PORTÚs, 2003: 43.

9 CAMÓN AzNAR, 1970: 384.

${ }^{10}$ Entre otros, Angulo, 1954: 225, Lafuente Ferrari, 1978: 190.

11 Documentación varia relativa a la adquisición se conserva en el Archivo del Museo del Prado, Madrid (AMP), caja 107 , legajo 13.05 , exp. 25 , a la que nos remitimos en sucesivas notas.
} 


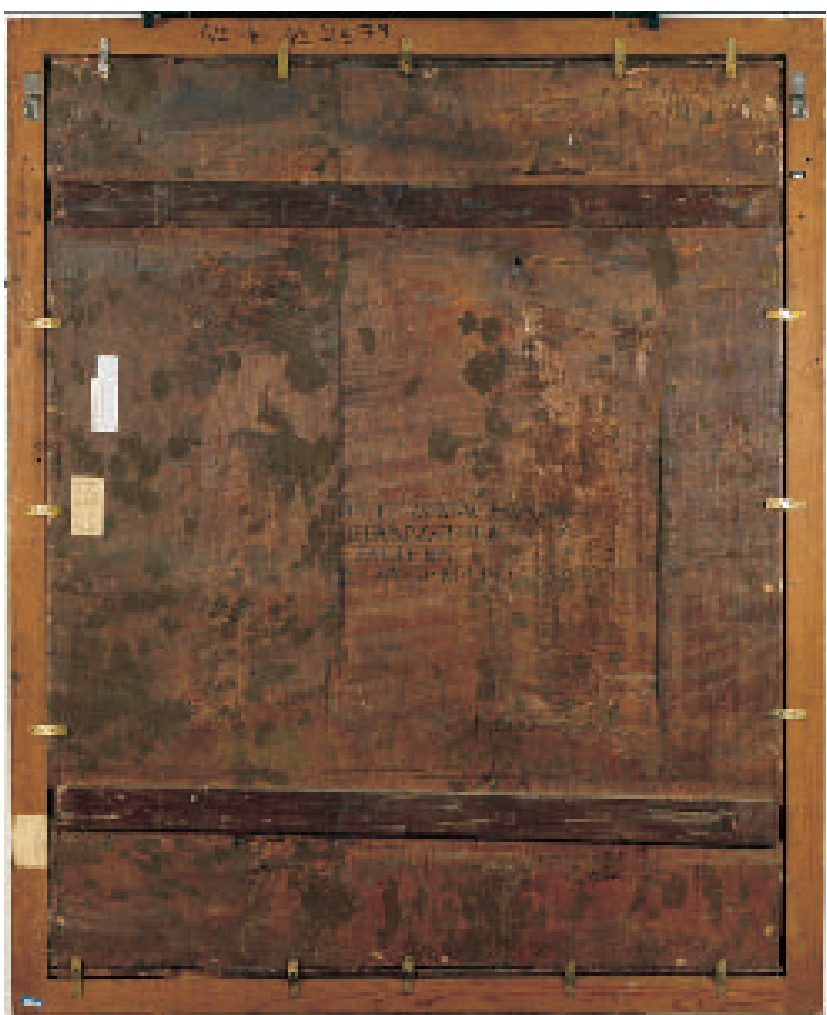

Fig. 2. Reverso del cuadro con La Virgen con el Niño $y$ las almas del purgatorio (Foto museo). taba en 1935 como pensionado en la Academia Española de Bellas Artes en Roma ${ }^{12}$, institución a la que se dirigió una persona provista de una fotografía del cuadro para que se le diera un veredicto ${ }^{13}$, puesto que con toda seguridad había observado en la inscripción del reverso el origen español de su autor (fig. 2). Este particular ( $\Delta$ PETRVS $\Delta$ MACHVCA $\mathbf{A}$ $\Delta$ ISPANVS $\Delta$ TOLETANVS $\mathbf{\Delta}$ ム FA CIEBAT $\mathbf{\Delta}$ A A (NNO) $\mathbf{D}(\mathrm{OMINI})$ $\Delta \mathrm{M} \Delta \mathrm{CCCCCXVII \Delta}$ ) era aducido por Pérez Comendador como motivo para que el cuadro pudiera interesarle al Prado: el autor era un español, se aportaba su localidad de nacimiento, aparecía en su condición de pintor cuando era "conocido principalmente como arquitecto", y de quien probablemente no habría obra pictórica conservada en España. También el intermediario del propietario consideraba la inscripción de extraordinaria importancia por los mismos moti$\operatorname{vos}^{14}$.

El cuadro era propiedad de un particular apellidado Pompei -la frase "familia propietaria" surge en la documentación-, a quien servía como intermediario un amigo suyo, Ugo Bonessi ${ }^{15}$, quien en sus cartas dirigidas a Pérez Comendador se expresa en francés. Este mediador había recabado información bibliográfica sobre Machuca a través del diccionario de Bénézit, por lo que menciona a Francisco de Holanda como autoridad, pero también a Lázaro Díaz del Valle y Palomino -ausentes en la fuente francesa-, insistiendo en que Machuca era citado al lado de grandes artistas como Miguel Ángel, Rafael y Leonardo, en especial tratado como gran intérprete de la "maniera de Raffaelo". A pesar de que confiesa que reconoce

12 Muerto en Madrid en 1981, estaba desde 1931 casado con la pintora francesa Madeleine Leroux (1906-85), con quien acudió a Spoleto a ver el cuadro. En las Exposiciones Nacionales de Bellas Artes había recibido medallas: de Tercera (1924), Segunda (1930) y Primera (1932). Fue pensionado en Roma entre 1934 y 1939, años que se consideran decisivos para su formación artística; en 1934 fue nombrado Correspondiente de la Real Academia de Bellas Artes de Santa Isabel de Hungría de Sevilla, cuando logra el Gran Premio de Roma, mientras que al siguiente se hace con el Premio Nacional de Escultura. De este año 1935 son sus quejas transmitidas a Francisco Javier Sánchez Cantón a propósito de la situación de la Academia de España (Carta de 1 de mayo), descontento generalizado entre los pensionados que protestaron en El Sol (Carta de 12 de mayo). Precisamente entre 1969 y 1973 ejerció de director de la referida institución (PÉrez-COMENDADOR, 1973. Exposición homenaje..., cat. exp., 1984. Hernández DíAz, 1986).

${ }^{13}$ Si bien se sugiere la intención que el propietario tenía de venderlo. Carta de Pérez Comendador dirigida a Sánchez Cantón (16-01-1935).

${ }^{14}$ Carta a Pérez Comendador (31-03-1935).

15 Carta a Pérez Comendador, Roma, 15-02-1935.

Arch. esp. arte, LXXXv, 338, ABRIL-JUNIO 2012, 125-146, ISSN: 0004-0428 
que no se trata de una "chef d'oeuvre", es evidente su interés artístico, pero mucho más el histórico, indica, dada la inscripción del reverso en el que se especifica el lugar de origen del gran arquitecto, autor del palacio de Carlos V. En definitiva, consideraba que la adquisición sería "de gran interés para la historia del arte español", obra que por sí sola justificaría las referencias literarias de los contemporáneos de Machuca ${ }^{16}$.

La situación de La Virgen y las ánimas del Purgatorio en la ciudad de la Umbría no es transparente. No es extraño que se diga que se cree "procedente de una colección privada de Spoleto" 17 , y que incluso la denominen "pala di Spoleto"18. Nimias han sido las dudas sobre otro origen que no sea esta localidad ${ }^{19}$. Roberto Longhi la había puesto en conexión con los Collicola, apellido de una ilustre familia italiana de cuyos bienes habría una subasta precisamente en $1935^{20}$. En realidad, conviene cuestionar tal venta pública, al menos para esta pieza, ya que su primera referencia escrita es del 16 de enero, sin que se aluda a una reciente compra efectuada en la ciudad. A propósito, el mismo Longhi consideraba que no había ninguna prueba que justificara que la obra hubiera sido realizada para Spoleto.

Esta ciudad de la Umbría pertenecía entonces a los Estados Pontificios, por lo que no sería sospechoso que un pintor ligado a la cultura del Rafael romano pudiera estar allí activo o bien que el cuadro hubiera sido expedido desde Roma. Sin embargo, nunca se ha puesto en relación con la cultura artística de esa zona peninsular, debiendo ser Spoleto un nombre circunstancial en la vida artística de Machuca, simplemente vinculado al coleccionismo sin tradición histórica. De hecho, la iglesia de Santa María delle Grazie, con la que se podría relacionar el cuadro dada su iconografía, está construida con posterioridad a su ejecución pictórica. Ni siquiera la ciudad es mencionada por Mayer cuando se recoge la obra por primera vez en una fuente bibliográfica en $1937^{21}$. El propio Pérez Comendador indica en una carta dirigida a Sánchez Cantón que el cuadro se encontraba "ahora" en Spoleto, siendo, además, una adquisición de no hacía mucho tiempo: "Me dice [Bonessi, el mediador] que en el caso de que ahí [el Prado] pudiera interesar sería fácil adquirirlo por haberlo comprado barato" 22 .

Longhi consideraba el cuadro estilísticamente de "estrazione romana". Esta apreciación podría enlazar con lo dicho por Mayer, quien diera un veredicto por escrito a través de una carta en la que expresaba el interés que tenía la pieza ${ }^{23}$. La menciona en la edición de 1942 de su Historia de la pintura española, indicando que procede de "una colección particular de Roma"24. Esta consideración no es del todo fiable si tenemos en cuenta que el veredicto lo hace por carta, es decir, lo más probable a través de una fotografía, sin que haya visto personalmente el cuadro;

16 Carta a Pérez Comendador, Roma, 31-03-1935. Ugo Bonessi considera elevado su interés artístico: colorido, técnica admirable, dibujo, composición en general y particularmente la parte inferior con el purgatorio. Cuando Pérez Comendador vio el cuadro personalmente quedó entusiasmado: "tuve la impresión agradable de encontrar una cosa bastante superior a lo que yo me esperaba. El cuadro es bello de color y de claro oscuro, no es obra maestra como Vd. muy bien apreció ya por la fotografía pero sí bastante discreta y digna" (Carta a Sánchez Cantón, 19-02-1935).

${ }_{17}$ DACOS, 1986: 248-249.

18 Giusti; LeONe DE CASTRIS, 1985: 133.

19 Tan solo Fernando Marías no lo daba por seguro: “quizá de procedencia umbra" (1989: 285).

${ }^{20}$ Longhi, 1969: 69. El Palazzo Collicola fue construido en la primera mitad del siglo XVIII siendo habitado por la familia hasta su extinción por lo que sería adquirido por el ayuntamiento de Spoleto en 1932, hoy sede de la Galleria Civica d'Arte Moderna. Actualmente, tan solo un ciudadano con el apellido Pompei aparece entre los residentes en Spoleto, quien confiesa que en su familia no hay tradición de coleccionistas.

21 MAYer, 1937 (3. ${ }^{\text {a }}$ ed.), p. 120.

${ }^{22}$ Carta de 16-01-1935. Sin conocer su precisa fuente de información, Rosenthal indica que el cuadro "apareció en Spoleto poco antes de ser adquirido por el Museo del Prado" (1988: 13).

${ }^{23}$ Carta de Pérez Comendador a Sánchez Cantón, 19-02-1935. Nuevamente se le menciona en una carta de Bonessi de 31 de marzo, junto con "autres critiques d'art italiens".

${ }^{24}$ MAYer, 1942 (2. ${ }^{\text {a }}$ ed.), p. 190. 
además, el intermediario, Bonessi, siempre escribe desde Roma, donde al parecer residía. Su poca determinación sobre el estado físico de la pieza es su error en la cronología, repetido en las dos publicaciones ya citadas, al decir que está fechada en 1518, año que no se corresponde con el de la inscripción.

Aún conjeturando que el cuadro haya pertenecido a un coleccionista privado residente en Roma y de que su autor se vinculara con la cultura artística romana del segundo decenio del siglo XVI, otra ciudad, Nápoles, podría ser la primitiva procedencia del cuadro, al menos el área del virreinato. Tal es el origen que se le dio a Pérez Comendador: "El cuadro me dicen que fue comprado en Nápoles junto con un Morales y un veneziano y se encuentran ahora en Spoletto a dónde el referido señor [el intermediario] me ha prometido llevarme a verlo" ${ }^{25}$. El hecho de que haya sido adquirido en un grupo en el que había un cuadro que el propietario atribuía a Morales ${ }^{26}$ y una obra de origen veneciano hace pensar en la volatilidad del mercado, pero también que en su momento hubiera sido una posesión de un particular secularmente ligado a la corona española o proceda de un ámbito religioso de alguna manera afín a España.

El cuadro fue adquirido por 15.000 ptas., en un tira y afloja que puso a prueba la capacidad de resistencia del patronato del Museo del Prado dado que inicialmente se había ofertado por $30.000^{27}$. La caída también es explicable dada la aparente acuciosa necesidad que el propietario tenía, pues también llegó a ofrecer al museo español, como vemos, otro cuadro. Pérez Comendador sugería que el precio tendría que bajar: "He podido apreciar que la familia propietaria desea vender la tabla, por lo tanto el precio que el Sr. Bonessi da en su carta no creo que sea definitivo. Él espera una oferta de Vd. sea cual sea"28. El cuadro se encontraba ya en Madrid el 6 de junio, embalado en un transporte expedido vía Barcelona ${ }^{29}$. Su colocación durante largo tiempo en la galería central del museo contribuyó a la revalorización de Machuca como pintor ${ }^{30}$.

Las águilas del Renacimiento español (1941) constituye un punto de inflexión en el tratamiento artístico de Pedro Machuca: Gómez-Moreno le consagra un capítulo tanto en su condición de

${ }^{25}$ Carta a Sánchez Cantón, 16-01-1935.

${ }^{26}$ Pérez Comendador también le envió una fotografía de la obra a Sánchez Cantón, de la cual no consta información en las actas del patronato (Carta, 19-02-1935), ni en el material que sobre el pintor se conserva en el Archivo del Museo del Prado. Desconocemos a qué obra se refiere. Hay que tener en cuenta que en 1641 la Madonna della Purità del pintor extremeño fue donada por un sacerdote español, Bernardo de Mendoza, a la comunidad de Clérigos Regulares de Nápoles y trasladada a la basílica de San Paolo Maggiore.

27 En una carta de Pérez Comendador a Sánchez Cantón (1-04-1935) se indica que incluso se llegó a barajar el precio de 50.000 ó 60.000 ptas. En reunión del patronato de 21 de marzo de 1935 el subdirector comunica que Pérez Comendador le transmitió cómo en una carta de febrero firmada por el mediador se pide 30.000 ptas., pero que se le contestó que la cantidad era "desproporcionada al mérito y al estado del mercado" y que si no hacían una proposición "moderada" ni siquiera la presentarían al patronato (AMP, caja 1380, legajo 19.15, carp. 2, Acta n. ${ }^{\circ} 342$, fols. 53-53 vto), queja que surtió efecto rebajando la cifra a 18.000 ptas. Elías Tormo, presidente del patronato, solicitó un voto de confianza para el subdirector a fin de que trate de adquirirla en menor precio, si fuera posible. Una carta de Bonessi dirigida a Pérez Comendador habla del sacrificio que implicaba para el propietario bajar el precio hasta ese punto (Roma, 1-03-1935). Posteriormente se estableció la suma de 12.000 ptas., considerada "desastrosa" por parte del propietario quien sugiere la de 15.000 (Carta de Ugo Bonessi, Roma, 31-03-1935). El 25 de abril se autorizó a E. Tormo, uno de los vocales del patronato, y a Sánchez Cantón, retirar el dinero para efectuar el pago (Acta n. ${ }^{\circ} 344$, fol. 55). Para evitar impuestos, se hace por medio de Pérez Comendador a través del Crédito Italiano con sede en Florencia (Recibo, 30-04-1935; carta de Pérez Comendador, 1-05-1935; carta de Sánchez Cantón al conde de Peña-Ramiro, 6-05-1935; carta de Pérez Comendador, 12-05-1935). El dinero se envía el 16 de mayo (Acta n. ${ }^{\circ}$ 345, fol. 56).

28 Carta a Sánchez Cantón, 19-02-1935.

29 Acta n. ${ }^{\circ} 346$, fol. 58 vto; cartas de Pérez Comendador 12 y 13-05-1935; carta de U. Bonessi a Pérez Comendador, Roma, 13-05-1935 (AMP, caja n. ${ }^{\circ}$ 107, legajo 13.05, exp. 25). Figura entre los cuadros adquiridos por gestión directa entre mayo de 1935 y mayo de 1936 (Acta n..$^{\circ}$ 361, 4-06-1936, fol. 80).

30 SÁNCHEZ CANTÓN, 1962, p. 72. 
pintor -sin demasiado entusiasmo- como de arquitecto, valorando también sus actuaciones de tasador y, significativamente, reflexionando sobre sus seguidores en el campo de la pintura, páginas que acogen por primera vez un aparato documental de archivo ${ }^{31}$. De la cantidad de obras que documenta en Granada y en localidades próximas tan solo se conservaba, según el estudioso, las piezas que podrían corresponderle del retablo de la Santa Cruz (Oración del Huerto, Prendimiento), en la Capilla Real; el retablo de San Pedro de Osma, en la catedral de Jaén; la Misa de San Gregorio, tabla central del retablo realizado para Santa María la Mayor de Úbeda y alguna pieza del de Viznar ${ }^{32}$. El tratamiento que Gómez-Moreno da a la Virgen con el Niño y las almas del Purgatorio no es muy positivo al emplear calificativos como "nada genial" y "nada seductor", aunque su autor "andaba por camino propio". Él es el primer historiador que menciona Spoleto como la procedencia del cuadro.

La pieza de la que estamos hablando fue un revulsivo en la imagen personal y artística de Machuca. Como hemos indicado, en 1935 pocas pinturas se relacionaban con él y su actividad como arquitecto en la Alhambra era lo que predominaba. No deja de ser significativo el comentario a la pieza que unos años después de la compra hiciera Sánchez Cantón: se trata de un cuadro firmado y fechado por el arquitecto toledano, que estuvo en Italia y que trazó el Palacio de Carlos $\mathrm{V}^{33}$. Es decir, una obra pictórica realizada por un arquitecto, con lo cual su identidad como pintor se solapaba ante la de constructor. Ahora quedaba reforzado su papel como pintor, materializándose la tradición literaria que lo tildaba de pintor notable y celebrado. La indiscutible calidad artística del cuadro aseveraba los encendidos elogios que sus contemporáneos dieron a sus pinturas. Según indicaba Sánchez Cantón en 1962, este cuadro había contribuido decisivamente a la valoración que desde hacía unos pocos años se estaba produciendo en torno a la actividad de Machuca como pintor. El hecho de estar realizado en Italia, según se desprende de la inscripción, implicaba la imagen de un artista español allí activo, dando testimonio ineludible de su estancia en la vecina península y de su fama como águila, en paralelo con otra de ellas, Alonso Berruguete (Francisco de Holanda).

\section{La cuestión de la inscripción}

Por entonces fue una revelación conocer el origen toledano de Machuca, precisado a través de la inscripción (" $\triangle$ ISPANVS $\Delta$ TOLETANVS $\Delta$ "), de tal manera que Mayer lo llama "Pedro Machuca de Toledo", ubicándolo en ese ámbito geográfico-cultural junto con artistas como los Comontes y Correa de Vivar ${ }^{34}$. Gómez-Moreno también apuntaría unos pocos años después cómo de Machuca se sabía desde hacía poco tiempo su origen toledano, precisamente gracias a la inscripción. La Ciudad Imperial y Uclés están entre las localidades donde trabajó el citado artista, según Lázaro de Velasco, pero a pesar de ello ni por tradición ni por consecuencias nada hay en el ambiente toledano que nos remita a Machuca. A Toledo se dirigió para actuar como tasador del grupo de la Transfiguración, realizado por Alonso Berruguete en el coro de la catedral (1548). Sin

31 GómeZ-Moreno, 1983 (1941), pp. 99 y ss.

32 También menciona el retablo de Nuestra Señora de la Consolación de la catedral de Jaén, que no asocia con la Sagrada Familia que se conserva en el citado templo, como hicieran Andreina Griseri (1959) y Jesús Hernández Perera (1960), y le atribuye dos tablas de la capilla de los Reyes Viejos de la catedral de Toledo. La Misa de San Gregorio no se conserva en la actualidad (se conoce mediante fotografía) mientras que sí existe la que daba por perdida, la Piedad (Valencia, catedral).

33 SÁnchez CANTÓn, 1952: 62. Incluso se ha considerado que fue su dedicación a la arquitectura por lo que "no tuvo tiempo de desarrollar su estilo ni de formar verdadera escuela, aunque se hayan identificado algunos discípulos" (Pita Andrade, 1985: 309).

34 MAYER, 1937 (3. ${ }^{\mathrm{a}}$ ed.), p. 120; 1942 (2. ${ }^{\mathrm{a}}$ ed.), p. 190. 


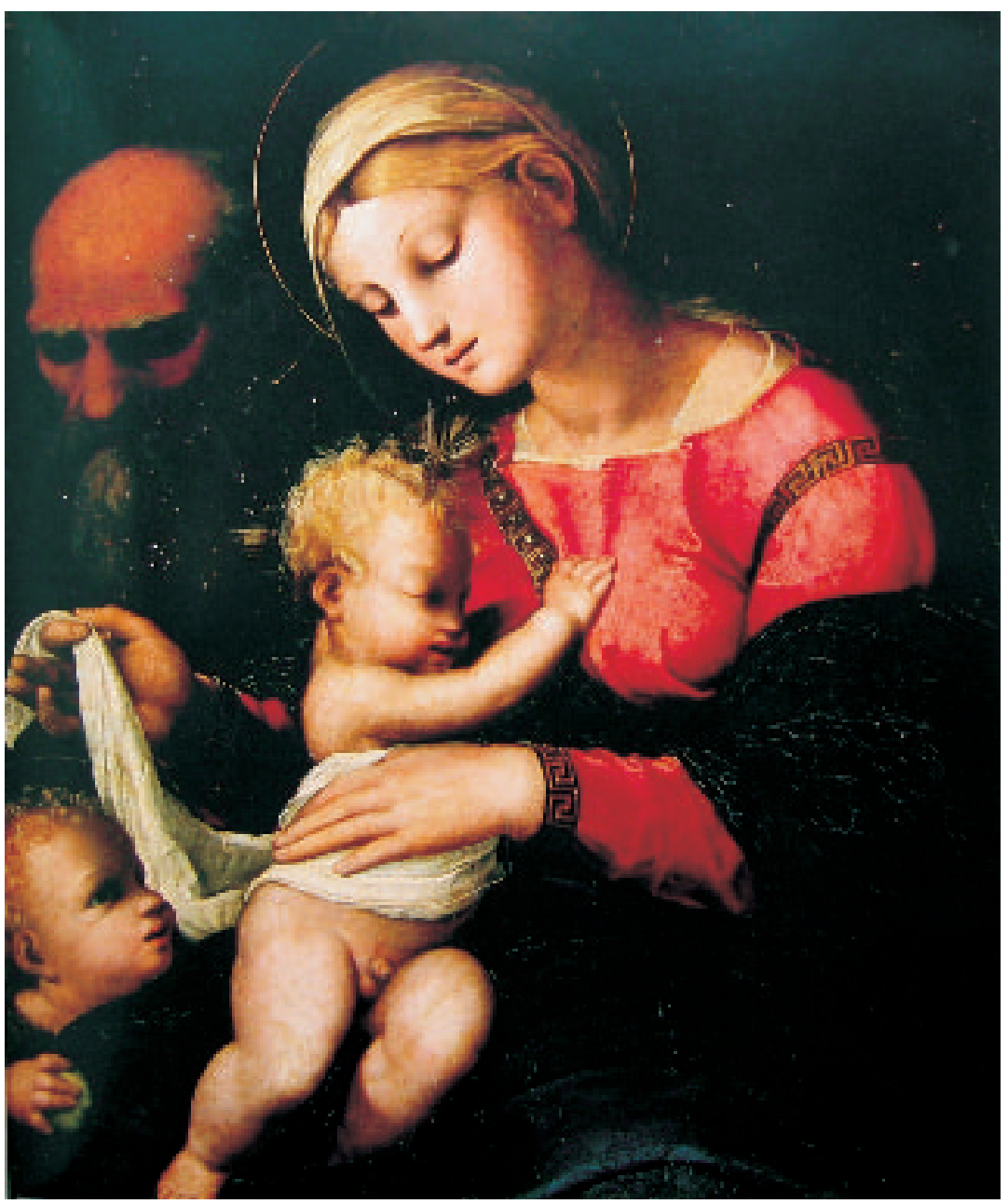

Fig. 3. Pedro Machuca. Sagrada Familia. Jaén, catedral.

embargo, la ausencia de testimonios suyos en Toledo y Uclés, e incluso de documentación, en contraste con lo que acaece en el reino de Granada y en Jaén, hace que Angulo trate a Machuca como "la gran figura con que precisa encabezar el pleno Renacimiento en Granada"35, adscripción válida para Camón, aunque considere la dificultad de ubicarlo "a una escuela determinada"

En cualquier caso, la dimensión de Machuca como pintor está sembrada de dudas. A la falta de unidad del conjunto de lo situado en torno a su nombre, se añade la incerteza de que lo documentado coincida con lo conservado y de que su recorrido italiano sea realmente el que la crítica italiana ha trazado desde Longhi hasta la actualidad. Lo más próximo a un Machuca que ha asimilado la cultura rafaelesca-leonardesca es la Sagrada Familia conservada en la catedral de Jaén (fig. 3), la cual podría corresponderse con la documentación relativa al retablo de la Consolación (1520). La relación estilística de esta tablita con la Virgen con el Niño y las almas del

\footnotetext{
35 Angulo, 1954: 225.

36 CAMÓN AZNAR, 1970: 383.
} 


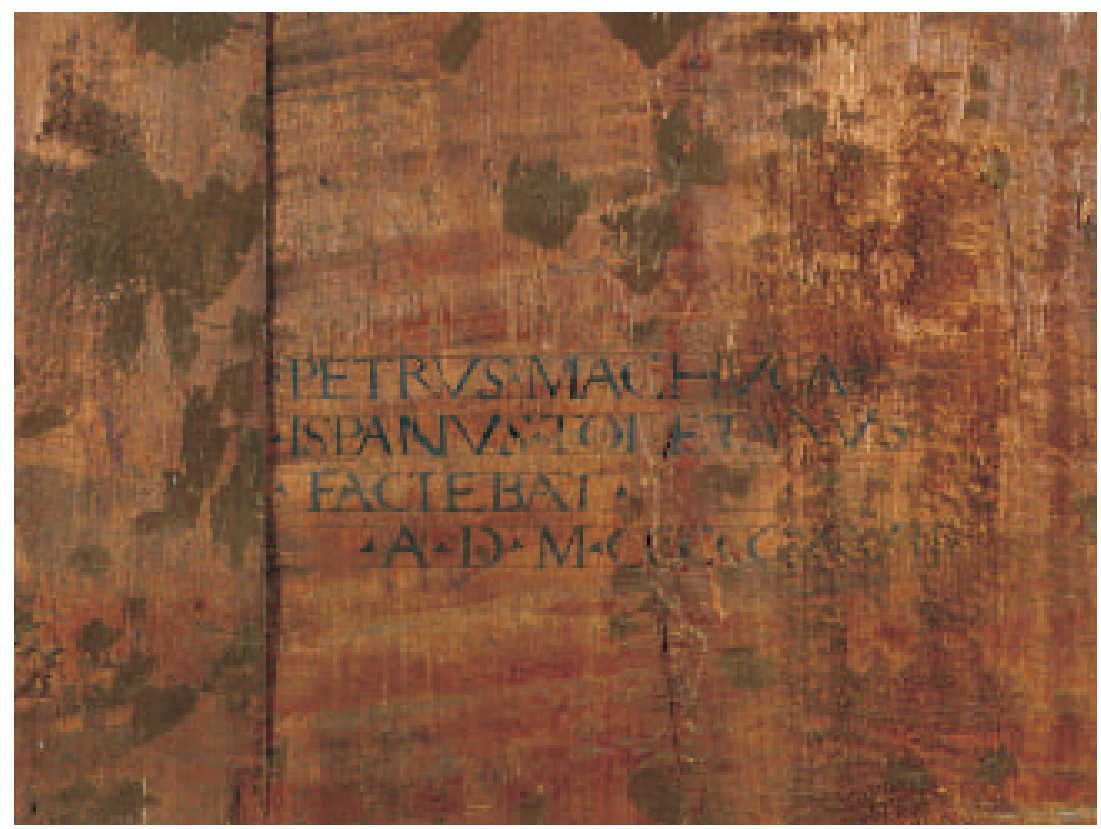

Fig. 4. Detalle del reverso del cuadro con La Virgen con el Niño y las almas del purgatorio (Foto Museo Nacional del Prado).

Purgatorio ${ }^{37}$, ésta con el Descendimiento, también en el Museo del Prado, a su vez con elementos apreciables en tablas del retablo de la Santa Cruz (h. 1521), como la que representa el Prendimiento, permiten establecer un núcleo con características similares.

Nadie ha puesto en duda la inscripción del cuadro (fig. 4). Es mencionada como algo extraordinario en la documentación de compra-venta, a fin de insistir en el interés de su adquisición por parte de un museo español dada su información: firma, consideración personal en su condición de artista y manifestación de orgullo en la realización de la obra de arte, origen del artista, fecha de ejecución e interés por fórmulas antiguas en la escritura. Curiosamente, no habla de ella Mayer cuando menciona el cuadro por primera vez, indicando tan solo que la pintura está fechada, aunque confunde el año, 1518 y no 1517, error que repetirá años más tarde. Es Gómez-Moreno en 1941 quien la transcribe en su conocida monografía sobre las águilas españolas. Aunque el soporte por el reverso ha sido manipulado, como se aprecia en los brochazos de color ocre que aparecen en diversas zonas aplicados en una restauración previa ${ }^{38}$, la tabla presenta un buen estado de conservación a pesar de haber sido atacada por xilófagos por lo que se ha debido reintegrar pequeñas porciones del soporte en la más reciente restauración efectuada con motivo de la inauguración de nuevas salas del Prado dedicadas al arte medieval y renacentista ${ }^{39}$.

\footnotetext{
37 GRISERI, 1959: 34-35, fig. 1.

38 Se considera que ha sido objeto de tres restauraciones, con anterioridad a la más reciente, dada la aparición de otros tantos tipos de estuco correspondientes a reintegraciones en su capa de preparación. Cuando ingresó en el Museo del Prado se produjo una de ellas, tal como precisa una etiqueta del reverso: “... Trabajo: limpieza y restauración/ a cargo: Seisdedos/ Término: 20-XII-1935".

39 Informe debido a Herlinda Cabrero, restauradora del Museo del Prado, del estado de conservación previo a su restauración y de los tratamientos de conservación y restauración realizados por ella, Museo Nacional del Prado, noviembre 2009).
} 
Indudablemente, es en extremo curioso encontrar pinturas firmadas y fechadas por el reverso, una zona nada visible para el espectador, práctica rara, pero no excluyente ${ }^{40}$. La tabla del Prado no es un cuadro de caballete en el sentido de que habría sido un cuadro de altar, engarzado en un mueble, para un destino concreto asociado al muro. La firma trasera conforma una de las tipologías en el amplio abanico de las firmas de la pintura renacentista ${ }^{41}$. La inscripción sale del campo figurativo, es decir, del plano pintado, aunque aquí no se trata de firmar en el marco -una variante de las firmas fuera del panel-, sino en una zona oculta a la visión del espectador. Es posible percatarse de firmas en este emplazamiento en piezas transportables como dípticos y trípticos, tal sucede en el tríptico de Giusto de Menabuoi de la National Gallery de Londres $(1367)^{42}$ y en un díptico del sienés Giovanni da Paolo, ya en el siglo XV ${ }^{43}$. Un ejemplo de la siguiente centuria cronológicamente muy próximo al cuadro del Prado es el Retrato de Galeazzo Sanvitale de Parmigianino (Nápoles, Museo di Capodimonte), firmado "OPVS D[E] MAZOLLA 1524 F"; sobre esta inscripción trasera alguna sombra se ha extendido acerca de la autoría del propio artista $^{44}$, pero en general se considera autógrafa ${ }^{45}$. Como vemos, los pintores sellan su identidad en una zona vetada al espectador, pero no por ello dejan de hacer hincapié en la autoafirmación, en dejar constancia de que ellos fueron sus creadores. Ejemplos previos a Machuca refuerzan la hipótesis de que el cuadro del Prado está entre los escasísimos ejemplos en que las firmas por el reverso pueden formar parte de la historia del cuadro desde su ejecución pictórica. Así, la inscripción que Filippino Lippi despliega en el reverso de la Adoración de los Reyes (1496) de los Uffizi, procedente del altar mayor del convento de San Donato en Scopeto, cerca de Florencia, ofrece información sobre el autor, su origen y la fecha de ejecución: "Philippus me pinsit de Lippis florentinus addi XXIX di marzo MCCCCLXXXXVI"46. Con posterioridad, Francesco Francia firmó por el reverso el Retrato de Pietro Cenni (Rotterdam, Boymans-Van Beuningen Museum $)^{47}$.

Otra hipótesis que se podría tener en cuenta es que la inscripción del cuadro del Prado sea de época o posterior, es decir, apócrifa, realizada con sumo cuidado a partir de la original desplegada en una zona externa al panel, puesto que se compró ya sin su marco ${ }^{48}$.

Desde la perspectiva de la conservación del cuadro, nada hace pensar que haya sido manipulado hasta el extremo de incorporar un elemento foráneo. La inscripción está realizada a pincel con materia de color negro, directamente sobre la madera sin preparación. Precisamente, negro de carbón vegetal se ha detectado entre los componentes de la ejecución pictórica. No se llevaron a cabo estudios químicos de la inscripción con motivo de su reciente restauración ya que los pigmentos negros no permiten establecer una datación. La analítica de este negro podría no ser determinante para afirmar o negar que la autoría del cuadro se deba a Machuca. Incluso es probable que tenga reforzado el color, como suele ocurrir en las inscripciones, por lo que sería ne-

40 Chastel, 1974: 11.

41 BURG, 2007: 321-322.

42 Davies, 1946, comentario a la lám. n. ${ }^{\circ} 13$

43 “OPUS/ IOHANNIS": OerTel, Frühe italienische Malerei in Altenburg, Berlín, 1961, p. 93, fig. 17.

44 FreEdBerg, 1971: 202-203; Chiusa la considera probablemente autógrafa, comparándola con la de una carta del pintor enviada a Giulio Romano (2001: 84).

45 Quintavalle, 1948: 40. Franklin, 2003: 90, n. ${ }^{\circ}$ 14. Fornari Schianchi y S. Ferino-Pagden, 2003: 26. EkSERDJIAN, 2006: 126

46 Esta inscripción no ha sido cuestionada en ningún momento (ZAMBRANO y NELSON, 2004, n. ${ }^{\circ}$ cat. 52 A).

47 “PE-/TRI CENNIS IMAGINE. M/ FRANCIA RAIBOLINUS/ MIRO ARTI-FICIO RE/ FORMATAM ETERNI/ TATI DEDIT UT PO/ STERIS CONSPICI/ ENTIBUS FIDEM/ FACERET QUANT/ A ESSET IN/ EO GRAVI/ TAS ATQ/ CLEMEN/ TI/ A" (BURG, 2007: 319).

48 Alguna obra atribuida a un artista, como la Virgen con el Niño de Francesco Francia del Musée du Louvre ("FRANCISCUS FRANCIA F. 1508”), lleva firma apócrifa, considerada como tal por el propio museo. 
cesario llevar a cabo una amplia toma de micromuestras para, finalmente, no poder asegurar la época de su aplicación.

Las inscripciones con la firma y la fecha en latín son comunes en la pintura y en la escultura del Renacimiento italiano, así como la indicación del origen del autor. Desde el punto de vista de la escritura, si bien es verdad que datar con absoluta seguridad las mayúsculas es una labor difícil, la inscripción implica una observación directa de los modelos epigráficos de la época romana consustancial con los intereses del Humanismo, imitando con un alto grado de perfección los esquemas monumentales de la época clásica. La escritura se despliega ordenada gracias a ocho líneas rectas, horizontales y paralelas, que marcan la madera con un instrumento inciso, a regla, definiendo la caja para ajustarse a un mismo formato. Éstas se prolongan más allá de la escritura ocupando el ancho de una de las tablas que conforman el panel. Incluso en grabados del Renacimiento donde se representan composiciones ambientadas en el mundo romano aparecen tabletas con inscripciones en que se llega a imitar este tipo de líneas como característica de la epigrafía romana. Digamos que en la tabla del Prado, el autor de la inscripción actúa como un grabador en piedra y como si realmente le fuera familiar este tipo de inscripciones asociadas a la arquitectura o a la escultura monumental. La escritura, en letras capitales clásicas, está emulando el claroscuro, los biseles y las formas cinceladas de la piedra.

La caja es de desarrollo apaisado, con cuatro renglones que no tienen como límite los mismos márgenes, como se advierte fundamentalmente en la derecha. A pesar del cuidado que se ha tenido en la ejecución de las letras, la composición no está centrada como habría de esperar en una inscripción de este tipo, lo que se podría interpretar como un carácter original, pues una falsificación procuraría adecuarse a un campo de impronta aún más clásica y de visualización más centrada. Los espacios intercaja de renglones están a la misma altura, en este caso vacíos al tratarse de letras mayúsculas a un mismo nivel. Estamos ante una escritura mayúscula inscrita en un sistema bilineal que constituye el cuerpo de las letras, con las líneas paralelas y horizontales tangentes a las letras. Las palabras se hallan separadas desde su inicio hasta su final mediante el interpunctio, el característico signo triangular que las centra. Los trazos de cada una de ellas son gruesos y delgados, alternando los tiempos, y el peso es perceptible en toda la escritura, de contundente impronta antica. Todo está en latín, incluso la numeración, aunque no siempre ocurre así en la pintura renacentista.

En cuanto al contenido, también está ordenada la información: en la primera línea aparece la identidad del artista, con su nombre y apellido; en la segunda, su origen; en el tercer renglón la palabra que indica que ejecutó la obra; la inscripción se cierra con la cuarta línea donde aparece la fecha, precedida por las iniciales de las palabras A(NNO), es decir "Año" y D(OMINI), o sea, "del Señor".

El término FACIEBAT, "lo hizo" o "lo ha hecho", encuentra en la Piedad del Vaticano de Miguel Ángel su más alta expresión y de hecho se ha considerado que es la primera vez que aparece esta fórmula antigua en una firma del Renacimiento ${ }^{49}$. Será empleado, con anterioridad a 1517, fecha del cuadro del Prado, por pintores y escultores como Filippino Lippi, Andrea Sansovino, Carpaccio, Giovanni Bellini, Marco Palmezzano, Sebastiano del Piombo ${ }^{50} \ldots$

Las iniciales A y D, referidas al Año del Señor, son frecuentes en las fechas de las obras de arte de los siglos XIV y XV, en menor medida en la siguiente centuria, en las que también llegan a aparecer ambas letras separadas por un signo. La cifra quinientos se despliega con la C repetida cinco veces, como en la Virgen con el Niño entronizada con santos y donantes (Florencia, Cenacolo di San Salvi), de 1500, obra de Raffaellino del Garbo ("RAPHAEL DE CAPONIBUS ME PINSIT AD MCCCCC") $)^{51}$ o en la Sacra conversazione de Marco Palmezzano (1520), si-

49 Goffen, 2001: 321-328. También será utilizado por Durero (1509).

${ }^{50}$ En la monografía de T. Burg aparecen listados de obras en que surge este término.

51 RuBIN, 2006: 568-569. 
guiendo así la normativa de los dos siglos precedentes ${ }^{52}$, a pesar de que lo habitual desde la primera década del XVI es que se exprese mediante la letra D equivalente a la referida cantidad, según se advierte en obras de Rafael y Sebastiano del Piombo.

En cuanto a la veracidad del contenido de la inscripción de la tabla del Prado, sería raro que se tratara de una suplantación. Si hubiera sido localizada sin este elemento, las características artísticas de la pintura, con vinculaciones con Rafael, Leonardo y Miguel Ángel, así como la iconografía la podrían hacer pasar por una pieza italiana, sin tener que recurrir a un pintor español casi desconocido. No nos imaginamos a un anticuario, ni siquiera a un historiador, acudir a las fuentes literarias de los siglos XVI al XVIII o al diccionario de Bénézit a la búsqueda de un español para la obra, si es que les ha parecido poco italiana. Según la correspondencia, sabemos que su propietario indagó sobre la identidad de Machuca a partir de la inscripción, es decir, que cuando fue por él comprada ya contaba con la inscripción. Como ya hemos dicho, en 1935 el catálogo pictórico de Machuca era mínimo, con dudas en cuanto a creaciones propias y sin una línea de continuidad, como se aprecia entre su intervención, poco definida, en el retablo de la Santa Cruz, de la Capilla Real, y el conjunto dedicado a San Pedro de Osma, de Jaén. Por ello, si la inscripción no fuera original habría poca base para darle una identidad tan precisa al cuadro.

Además, siendo Machuca un artista hasta entonces inscrito en el ámbito granadino, mayormente como arquitecto, no habría motivo para buscarle un origen que no sea Granada, en vez de Toledo. La mención a su condición de "español" deja constancia de su lejanía con respecto a su lugar de origen, característico de las obras hechas para o en otros países o ciudades ${ }^{53}$, mientras que la precisión de que es "toledano" induce a una peculiaridad aún más personal, ámbito geográfico que en cualquier caso no se apoya en datos documentales, a excepción de la presencia del artista en la Ciudad Imperial con motivo del examen de la Transfiguración de Alonso Berruguete en el coro de la catedral.

Ni una sombra se cierne acerca de la inscripción en la correspondencia ya mencionada sobre la compra-venta del cuadro. El primero que la menciona en una publicación científica es August Mayer en 1937 -y probablemente el primero en llevar a cabo un veredicto a través de un certificado epistolar- ${ }^{54}$, al que no se debe responsabilizar de ninguna manipulación del cuadro puesto que ni siquiera menciona la inscripción, se equivoca en la fecha y no cita a Rafael y Miguel Ángel como influencias, cuando aparecen en las fuentes literarias.

\section{¿Machuca y la Italia meridional?}

El cuadro de Machuca es italiano en cuanto a soporte ${ }^{55}$-madera de chopo ${ }^{56}$ - y ejecución, así como por su iconografía, dentro de la tipología de la "Madonna delle Grazie con le anime del purgatorio" ${ }^{57}$. Dada su adquisición en Nápoles y el extraordinario desarrollo que este tema tuvo

$52 \mathrm{Al}$ respecto, véase los listados que aparecen en la monografía de T. BuRG.

53 Goffen, 2001: 308.

54 "Ellos [propietario, intermediario] tenían mayores pretensiones [económicas] concebidas por el cuadro mismo y porque Mayer en carta que me enseñaron les corroboraba su interés" (Carta de Pérez Comendador a Sánchez Cantón, 19 de febrero de 1935).

55 El panel, de $167 \mathrm{~cm}$. de alto por $132 \mathrm{~cm}$. de ancho, con una profundidad de $3,8 \mathrm{~cm}$., está constituido por tres tablas dispuestas con la beta en sentido vertical, ensambladas por dos barrotes horizontales situados en su reverso encastrados en corredera en forma de cola de milano.

${ }^{56}$ Esta característica está recogida en los catálogos del museo desde el primer momento que se le cita (1942: 347, n. ${ }^{\circ}$ 2579) y es mencionada significativamente por LAFUENTE FERRARI a partir del catálogo del Museo del Prado (1978: 190).

${ }^{57}$ Reau, 1957: 123. Gonçalves, 1959, n. ${ }^{\circ}$ 6: 1-37, fig. 4. Strazzullo, 1987, fig. 13; Scaramella, 1991, fig. 42. 
en la ciudad y en general en la Campania habría que reflexionar sobre la posibilidad de que el cuadro haya sido realizado allí o enviado desde Roma mediante un encargo.

Desde la historiografía italiana posterior a Longhi y su escuela, hay quienes sitúan a Machuca a caballo entre Roma-Florencia-Nápoles, pero en general no se ha podido definir una cronología exacta para este itinerario. Tampoco es unánime el criterio de ubicarle en Nápoles de un modo intermitente o con motivo de su regreso, probablemente en 1519 o principios del siguiente año. Su presencia en la Italia meridional se ha venido sustentando en hechos nada contundentes ${ }^{58}$.

Uno de ellos se basa en la suposición de una participación como arquitecto en la capilla Caracciolo di Vico, junto con Siloé y Ordóñez, otros dos "comprimari” de la manera italiana ${ }^{59}$. Otro se relaciona con la existencia de obras suyas en la zona, una de estas el Descendimiento del Museo del Prado. Palermo es la localidad que se menciona como su procedencia y la crítica italiana insiste en ello desde que Longhi la publicara ${ }^{60}$. Sin embargo, se han expresado dudas de su realización en esta ciudad siciliana e incluso en la propia Italia ${ }^{61}$. Se trata de una tabla que en el momento de su primera venta documentada en 1904 (Catalogue des Tableaux Anciens et Modernes...) se dice que había sido atribuida por Venturi a Lorenzo Lotto y que procedía de una iglesia de la citada localidad, a pesar de que su marco se daba por obra de A. Berruguete, siendo alta su consideración ${ }^{62}$. Sin embargo, según Longhi el historiador italiano solamente había conjeturado su filiación española. En la bibliografía posterior no se menciona ese origen siciliano ${ }^{63}$ y la primera vez que el cuadro es recogido por un catálogo del Prado (1972), tampoco se hace constancia de esa procedencia ${ }^{64}$. Ahora bien, en la historiografía italiana posterior es una constante su adscripción a Palermo, ya sea como prueba de la presencia física del artista o como pieza enviada, poniéndola en relación con la llegada coetánea de la Subida al Calvario ("Pasmo de Sicilia") de Rafael, cual dos hitos en el ambiente cultural de la zona ${ }^{65}$. Dado lo incierto de la procedencia, habría que poner en duda el origen siciliano de la obra. Últimamente la historiografía italiana ha retomado el tema de los "comprimari" españoles de la manera italiana considerando el Descendimiento del Prado como un "brano di altissimo livello, e certo uno dei risultati più elevati della poetica classico-manierista del secondo decenio" "66.

Mientras que del cuadro no hay constancia de su repercusión entre los artistas italianos, del dibujo preparatorio ${ }^{67}$ sí nos han llegado copias, totales o parciales, en soportes de papel ${ }^{68}$, al

58 Paola Giusti y Pierluigi Leone de CAstris son quienes más han apostado por la presencia de Machuca en Nápoles en diversas publicaciones monográficas y artículos $(1985,1988)$. NiCOLE DACOS también aborda positivamente la presencia de Machuca en la Italia meridional, incluyendo Nápoles (1986: 248-249), así como FrANCESCO ABBATE (2001: 3-9, 83 y ss.).

59 Bologna, 1988-89 (1990): 353-361.

${ }^{60}$ LONGHI, 1953: 3-15.

${ }^{61}$ Post, 1958: 740-742. Dacos, 1984, nota 32.

62 1904: 26, con reproducción de la obra (n. ${ }^{\circ}$ P3017).

63 BALDASS, 1927: 179, fig. 6 (sin marco). La da por obra de un pintor del norte de Italia, de hacia 1530, bajo la influencia del grabado de Marcantonio Raimondi, con el cual, no obstante, no tiene nada que ver. Años más tarde se adscribe a Pedro de Campaña (Catalogue of the Hungarian State..., 1944, n. ${ }^{\circ} 2061$ ).

${ }^{64}$ En el catálogo del Museo del Prado de 1972 (n. $\left.{ }^{\circ} 3017\right)$, en el que se basa el más reciente, se cae en un error al decir que pertenecía a los Bourgeois Frères "antes de 1870", y no desde antes de esa fecha.

65 CALI, 2000: 643.

${ }^{66}$ CHIUSA: 188.

${ }^{67}$ Griseri, 1957: 13-21. Boubli, 2002, n. ${ }^{\circ} 12$.

68 Grisalla en el Louvre (Boubli, 2002: 39, n. $\left.{ }^{\circ} 18\right)$, copia parcial atribuida a Biagio Pupini perteneciente a la colección Morton B. Harris de Nueva York (Griswold y Wolk-Simon, 1993, n. ${ }^{\circ}$ 3); del mismo tamaño que el ejemplar de Machuca es el dibujo de la Albertina de Viena, considerado autógrafo por el propio museo.

Arch. esp. arte, LXXXv, 338, ABRIL-JUNIO 2012, 125-146, ISSN: 0004-0428 


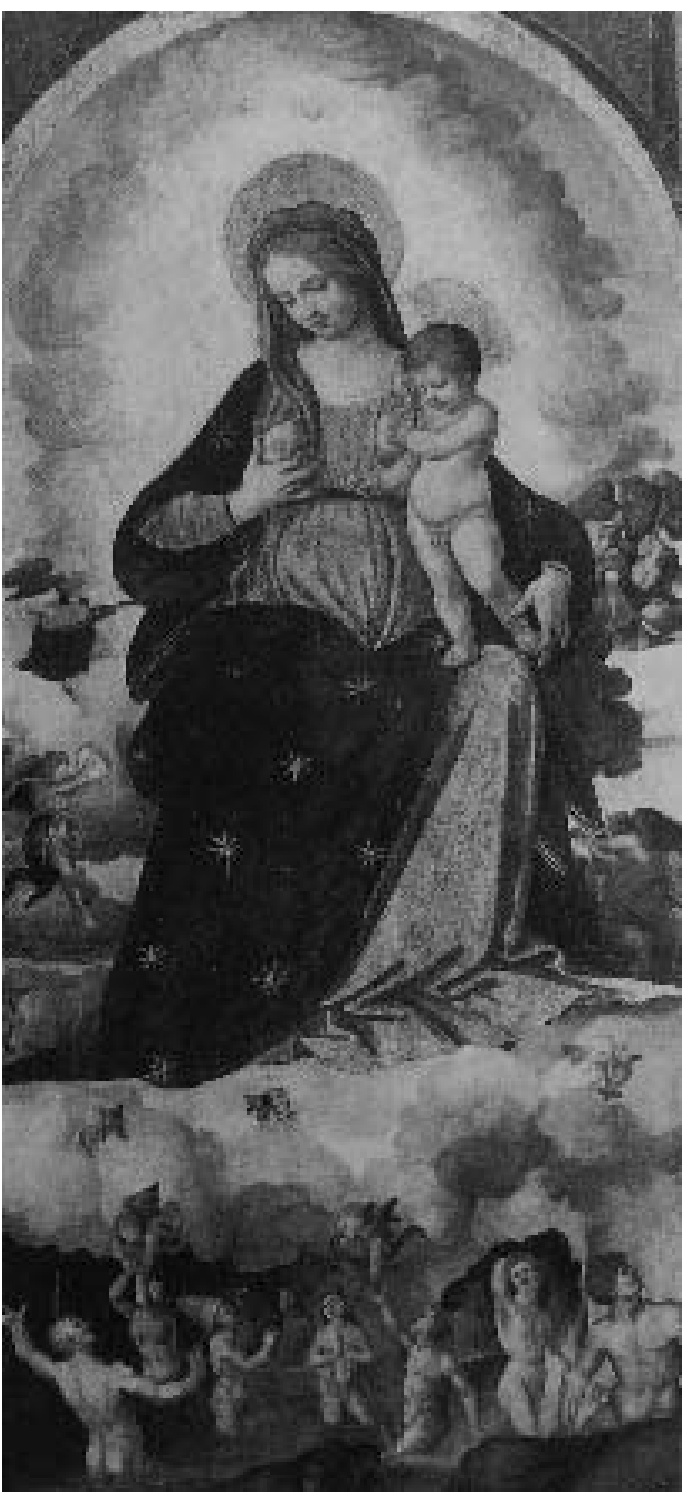

fresco ${ }^{69}$ y en madera ${ }^{70}$. Es decir, que estamos ante un cuadro que se divulgó a través del dibujo, ya sea del original como de copias. La cuestión se hace más compleja al constatar su presencia, mermada, en un retablo de Esparza de Galar (Navarra) y en la reja de la Capilla Real de Granada (1518-23), en ambos casos dependientes de la composición del dibujo ${ }^{71}$.

Otro elemento que se ha tenido en cuenta para considerar un Machuca napolitano es a propósito de la proyección de una de las Marías del Llanto sobre Cristo muerto, otro dibujo considerado de Machuca $^{72}$, en el mismo asunto que Marco Cardisco realizó por los años treinta en la luneta del políptico de Santa María a Parete en Liveri, cerca de Nola, próxima a Nápoles ${ }^{73}$. Simultáneamente se conjetura que debió existir por la zona la tabla definitiva. Dos figuras de este dibujo, Cristo y una de las Marías, reaparecen en la tabla de la Piedad de Santa María la Mayor de Úbeda (Valencia, catedral) atribuida a Machuca ${ }^{74}$.

Según vemos, en ambos casos citados es la volatilidad del material gráfico lo que hace posible la aparición de copias generales o parciales en diferentes soportes, y no solamente en Italia, sin que conozcamos su traducción al grabado, si bien hay que considerar cómo dos creaciones de Machuca se fueron imponiendo de una forma $u$ otra en distintos puntos de la Italia central y meridional.

Fig. 5. Andrea Sabatini. Madonna delle Grazie y las almas del purgatorio. Hacia 1511. San Valentino Torio, iglesia de San Giacomo Apostolo.

${ }^{69}$ Con variantes, en un muro del antiguo convento de San Salvatore, en Bolonia, obra de Innocenzo Francucci, llamado Innocenzo da Imola (FAIETTI, 2002: 49-54).

${ }^{70}$ De un artista de la Italia meridional debe ser el Descendimiento de colección particular que años atrás ha estado atribuido a Machuca (GiUSTI y LeONE DE CASTRIS, 1985: 48, fig. 2.8; Ávila, 2000, n.ํ167).

71 ÁvilA, 1987: 153, fig. 4; 1995: 181-186, figs. 4-8. En el primer ejemplo se aprecia que el pintor ha tenido en cuenta también otro modelo, la Santa Catalina del grabado de los Cinco santos de Marcantonio Raimondi a partir de un dibujo de Rafael o de su entorno. En el segundo, un ambiente tan familiar para Machuca, resulta curioso que dependiendo en general de la composición del dibujo, varía la disposición de las piernas de los santos varones como si su autor tuviera en cuenta otras copias o su traducción al grabado.

72 Boubli, 2002: 34-36, n. ${ }^{\circ} 13$.

73 Giusti y Leone de CAstris, 1988: 234.

74 Gómez-Moreno, 1983 (1941): 103; Benito Domenech, 1985: 45-46. 
Otra vía en la conexión Machuca-Italia meridional se centraría en la repercusión de la Virgen con el Niño y las ánimas del purgatorio en algunas obras del área, como en un encargo de diciembre de 1517 a Agostino Tesauro para la iglesia de Santa Maria della Peschiera de San Cesareo, en la provincia salernitana, cotejo que no ha dejado de ser contestado atribuyéndolo a modelos comunes ${ }^{75}$. Otra obra, ahora de Andrea Sabatini da Salerno, de 1519 (Matrimonio místico de Santa Catalina, Nocera Inferiore, iglesia de San Francesco), ha sido objeto de atención al considerarla deudora del cuadro del Prado, del que incluso se llega a hablar de prototipo ${ }^{76}$. Más aventurada es la atribución a Machuca de la tabla con la Dormición y Ascensión de la Virgen del Museo di Capodimonte, conectada con un dibujo con el mismo tema conservado en el Louvre y a él adjudicado ${ }^{77}$, composición parcialmente proyectada sobre un panel considerado a su vez de Marco Cardisco. La culminación de este proceder tendente a vampirizar a Machuca para la causa italiana hasta límites insospechados es su presencia entre los pintores activos en la Campania en las salas del prestigioso museo napolitano a través de la tabla mencionada, dada como obra segura del artista creando

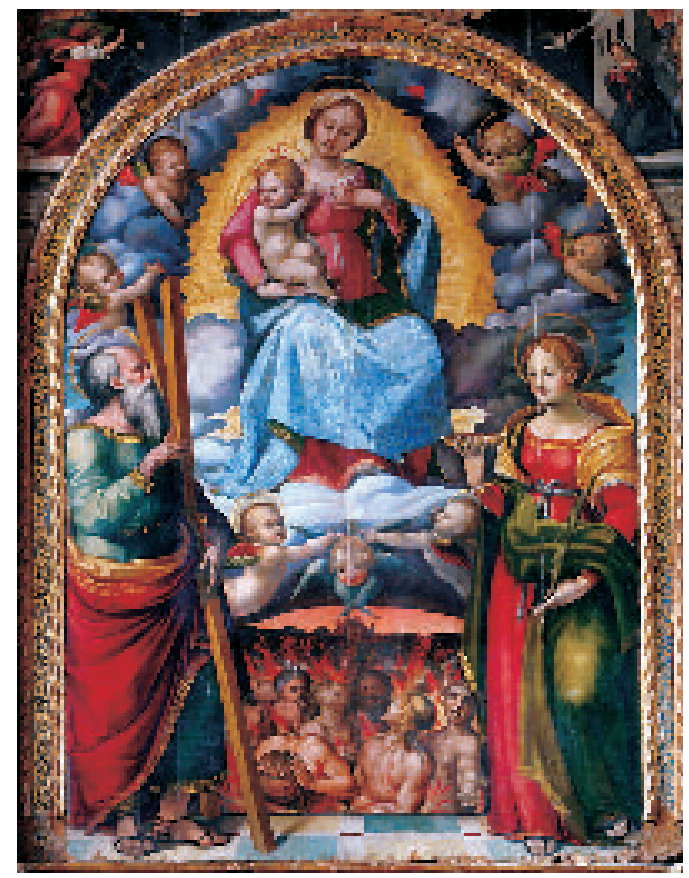

Fig. 6. Agostino Tesauro. Retablo con la Madonna delle Grazie entre San Andrés y Santa Lucía. Fines de 1517. Cava de'Tirreni, Museo dell'Abbazia. así una imagen distorsionada de Machuca.

La relación con Nápoles no se detiene, bajo la perspectiva de la más reciente crítica italiana, en el terreno de la pintura sino que se extiende al de la miniatura, haciéndole surgir del hipotético taller italiano de Pedro de Aponte ${ }^{78}$, con obras sin ninguna vinculación estilística con los cuadros del Museo del Prado y la Sagrada Familia de la catedral de Jaén, tablas que serían de ejecución individual y que forman una unidad lingüística.

El hecho de que la Virgen con el Niño y las almas del purgatorio de Machuca se haya comprado en Nápoles podría reforzar la apropiación antes descrita, dilatando el espacio de actividad del artista, aproximándolo a un terreno históricamente vinculado a España, siguiendo la estela de otros españoles, y cohabitando con las otras "águilas" asimiladoras de la nueva "maniera". Sin embargo, no hay ningún elemento certero que demuestre que el cuadro y/o el pintor estuvieran en la zona, ni tampoco es evidente su proyección en tablas italianas del entorno napolitano según ha detectado la crítica italiana ${ }^{79}$. A pesar de ello, el tema es habitual en Nápoles y en su entorno, antes y durante la estancia en Italia de Machuca (figs. 5, 6), considerándose que entre 1510 y

75 Kalby, 1973: 29-38; 1975: 36, 38, 50. D’Aniello, 1986: 142.

76 Giovanni Previtali las reproduce correlativamente a fin de que se aprecien las supuestas similitudes (1978, figs. 24, 25). Al respecto, también FrANCESCO ABBATE aprecia sintonías entre una obra y otra (1986: 140-141).

77 LeONE DE CASTRIS, 1992-1993. Boubli, 2002, n. ${ }^{\circ} 14$.

78 LEONE DE CASTRIS, 2005; 2007.

${ }^{79}$ Agostino Tesauro. Retablo con la Madonna delle Grazie entre San Andrés y Santa Lucía. Cava de'Tirreni, Museo dell'Abbazia; Andrea Sabatini. Matrimonio místico de Santa Catalina. Nocera Inferiore, iglesia de San Francesco. 


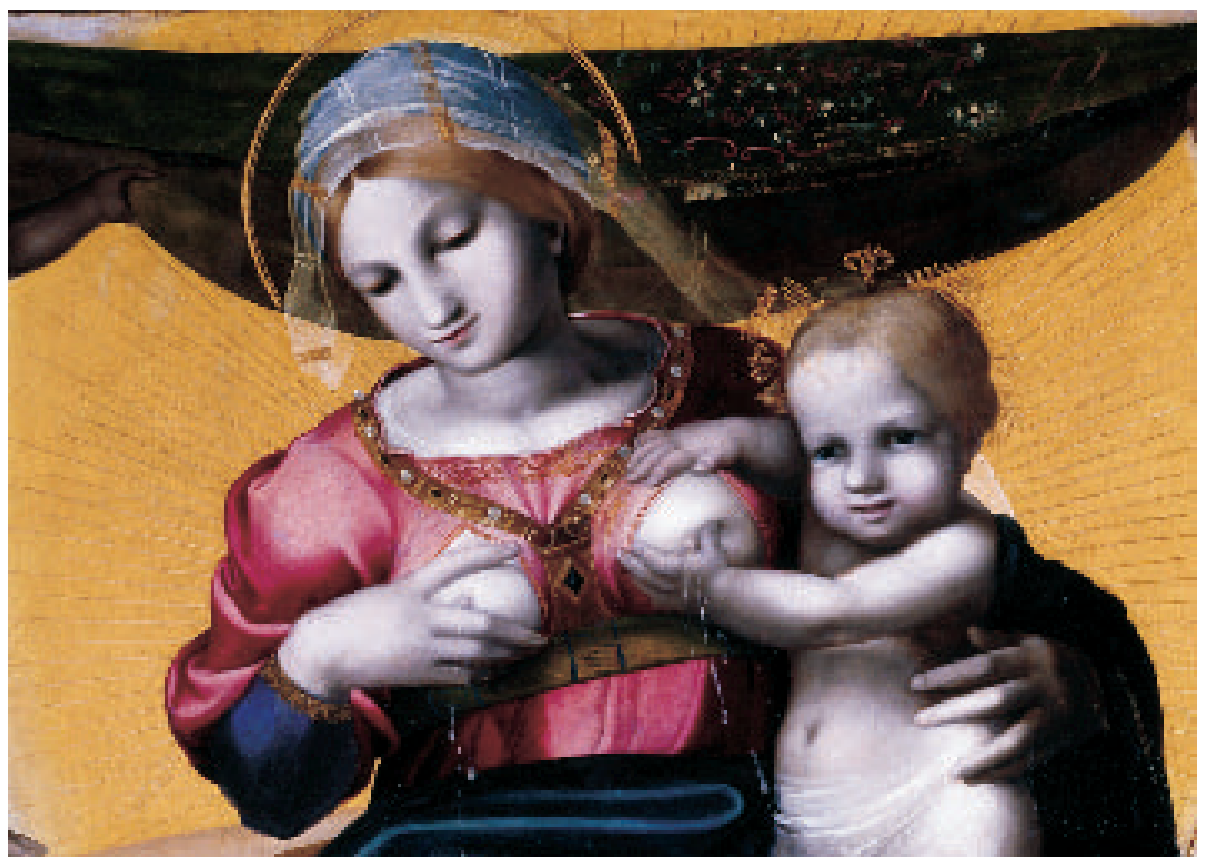

Fig. 7. Detalle de La Virgen con el Niño y las almas del purgatorio, de Pedro Machuca (Foto museo).

1530 es el periodo de mayor difusión del asunto, interpretado bajo las mismas constantes que pone en práctica Machuca por diversos artistas (también escultores) y diferentes versiones, según las variantes que con el paso de los años se van sucediendo. Por ejemplo, las nubes fueron marcando la franja divisoria entre el Purgatorio y el Cielo y la virgen terminará por aparecer no de pie sino sentada sobre las nubes por donde revolotean los ángeles. El cuadro del Museo del Prado trasciende la interpretación iconográfica desarrollada en Italia hasta el momento, al presentar variantes y alejarse de lo anecdótico y narrativo, en el marco de un empaque de grandiosidad, carga emotiva y sensualidad que sitúa a la obra en un contexto pictórico italiano absorbiendo a los clásicos renacentistas con propia personalidad.

La "Madonna delle Grazie" es una tipología iconográfica que versiona el tema de la Virgen de la Leche. María aparece como madre, corredentora, mediadora y dispensadora de las gracias, materializadas a través de la sustancia láctea que mitiga el sufrimiento de las almas del Purgatorio a la espera de su ascensión al cielo. El Niño es copartícipe de esta acción de bondad apretando el seno de su madre para hacer brotar la leche que metafóricamente reconforta y aporta esperanza a los que padecen entre las llamas del Purgatorio. Los chorros y las gotas de leche que salpican la tabla de arriba hacia abajo (fig. 7), las miradas de María y de las cabezas que se alzan desde el Purgatorio, así como el diferente tratamiento de color y de luz entre el Cielo y el Purgatorio, son las claves del cuadro y en ellas residen no solamente valoraciones formales sino conceptuales. El tema de la ostentatio uberum también tiene cabida en la iconografía de la "Madonna delle Grazie" 80 , en paralelo con la ostentatio genitalium, otro referente de la iconografía cristiana que viene a insistir en la naturaleza humana de $\mathrm{Cristo}^{81}$. Como oposición se encuentran

\footnotetext{
80 Pluchinotta, 1997.

81 STEINBERG, 1989.
} 
los pies calzados de la virgen, un elemento ligado al concepto del decoro en que se movió el artista mientras que en modelos rafaelescos están al descubierto. En el cuadro la desnudez no se interpreta en clave de preocupación exclusivamente anatómica sino como expresión de un desarrollo temático de cariz religioso. Se considera que entre los precedentes del asunto de la "Madonna delle Grazie col purgatorio" está la tabla de Antoni Peris que forma parte del retablo de la Virgen de la Leche (fig. 8), pintada con anterioridad a 1415 , en que los devotos de diversas condiciones sociales arrodillados recogen en diferentes recipientes la leche que procede del seno de la Virgen lactante $^{82}$, insistiendo en su maternidad universal y en su papel de mediadora ${ }^{83}$ : aquí se encuentra el concepto de la lactancia universal de María que proporciona gracias para todos los situados a sus pies. María no solamente está amamantando a su hijo sino como Madre universal facilita leche a los devotos, en cuanto dispensadora de los dones que Dios concede.

Manteniéndose en tantos aspectos deudor de Rafael, el pintor español aporta novedades en el tratamiento compositivo con la Virgen y el Niño sentada encima de las nubes sobre un trono protegido por un dosel suspendido en el aire gracias a la intervención de dos ángeles. El Purgatorio, a los mismos pies de María, no solamente es un impreciso espacio físico, a propósito angosto para inci-

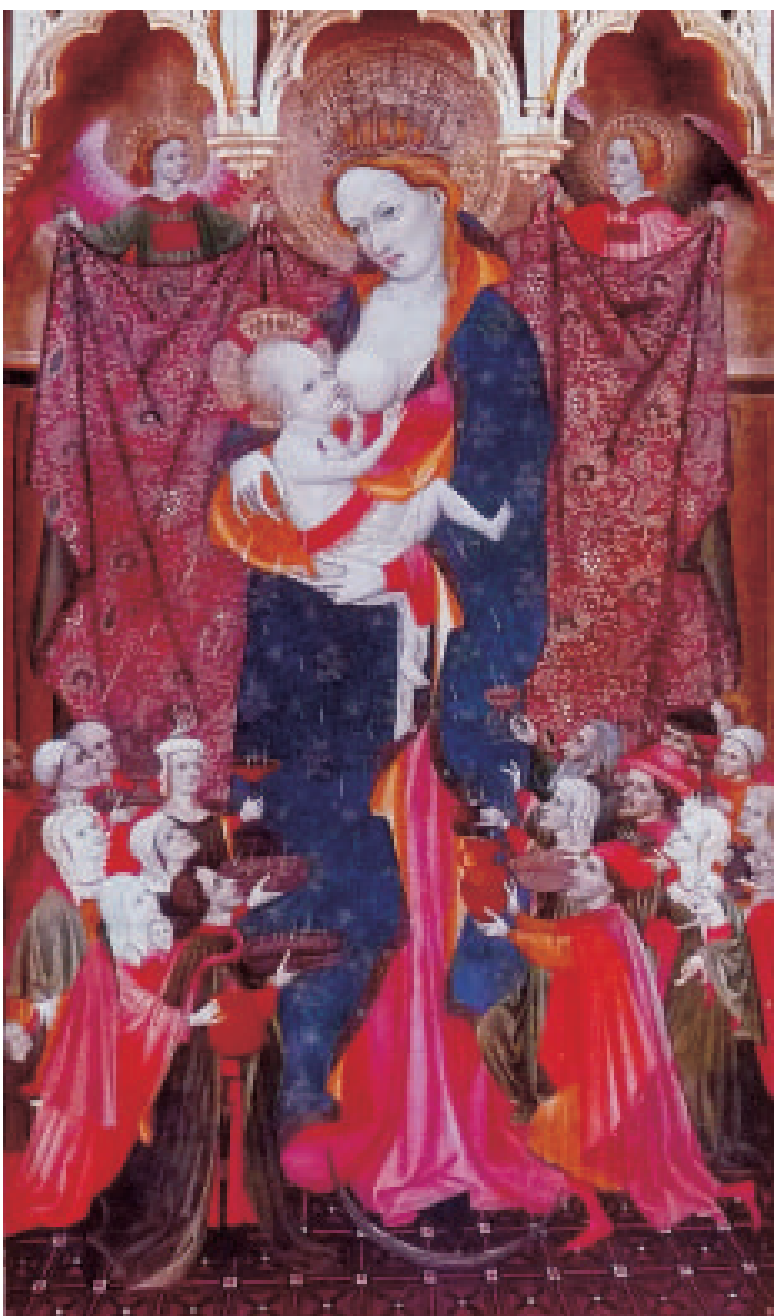

Fig. 8. Antoni Peris. Tabla central del retablo de la Virgen de la Leche. Valencia, Museu de Belles Arts.

dir en la opresión anímica; también es un

lugar para las emociones del tormento, que afectan solamente a hombres, y las ansias de esperanza, surgidas de cuerpos deseosos de cualquier gota de leche que aplaque los dolores del alma, tras cuyo líquido refrescante se aproximan, desde una zona muy iluminada a causa del poderoso fuego, como si se tratara de la boca del Infierno (fig. 9), unas figuras desnudas desgarradas por los tormentos y ansiosas por recibir el alimento reconfortante que les mantendrá a la expectativa de alcanzar la contemplación de la luz divina ${ }^{84}$.

\footnotetext{
82 SCARAmella, op. cit., p. 47.

83 "Antonio Peris. Retablo de la Virgen de la Leche", en La memoria recobrada. Pintura valenciana recuperada de los siglos XIV-XVI, catálogo de exposición, Valencia, n. ${ }^{\circ}$ 16, pp. 64-67, 259.

${ }^{84}$ No creemos que se trate de "almas liberadas", dos de las cuales han sido identificadas, dubitativamente, con Adán y Eva (Carlos Vy su tiempo, 1958, n. ${ }^{\circ} 63$ ).
} 


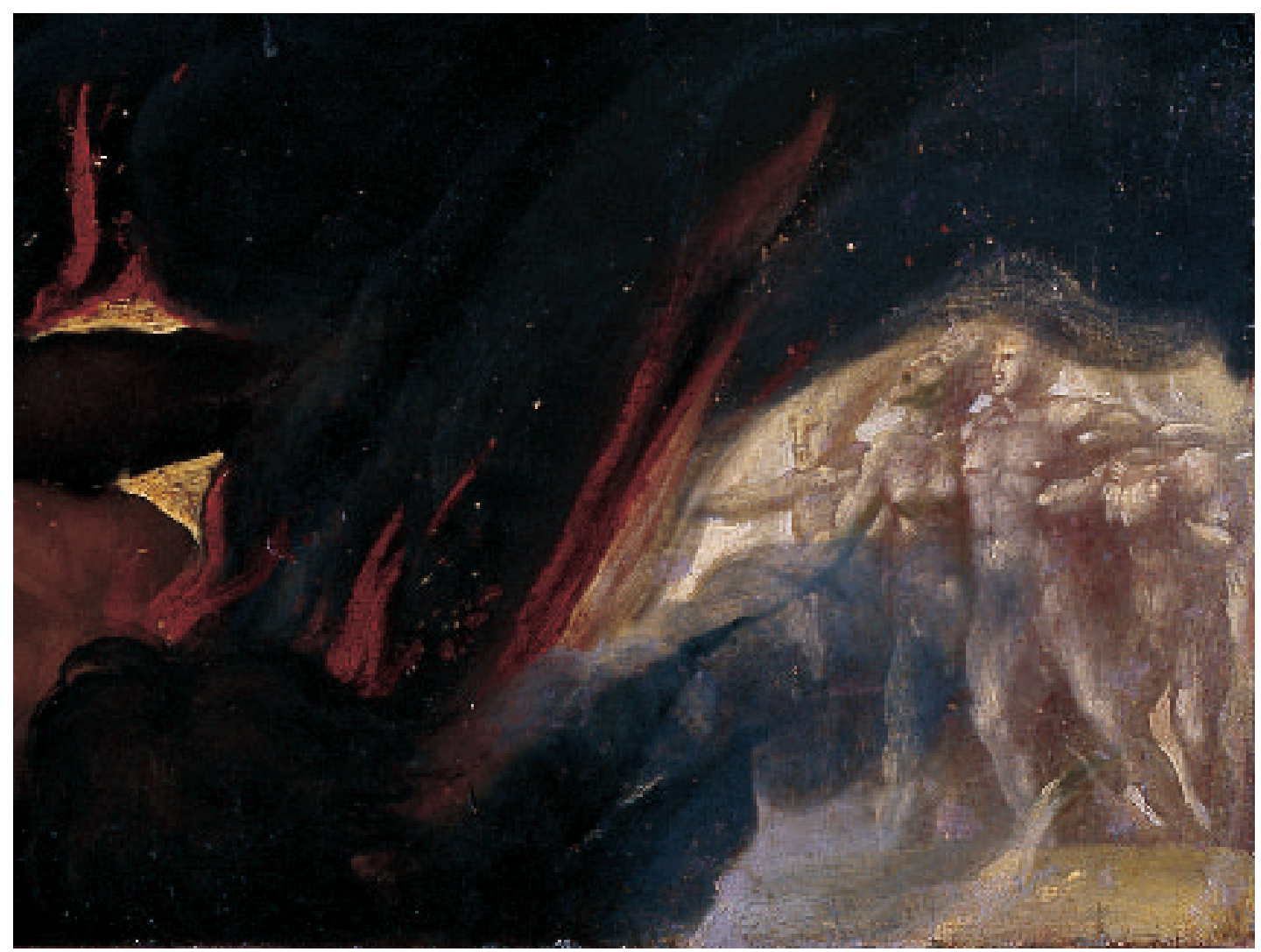

Fig. 9. Detalle de la parte inferior derecha de La Virgen con el Niño y las almas del purgatorio, de Pedro Machuca (Foto museo).

Se ha venido manifestando la rareza de esta iconografía, más aún en el arte español ${ }^{85}$, sin embargo, tal como hicieran Gómez-Moreno, Angulo, Rosenthal y otros ${ }^{86}$, debe entenderse bajo la perspectiva de la cultura italiana, si bien en la pintura española del siglo XV no es extraño encontrarnos con tablas en que la leche como alimento de valor universal viene a ser metáfora del amor de María hacia la humanidad, más allá de la común interpretación de la Virgen amamantando a su hijo ${ }^{87}$.

85 Portús, 2003: 43. Hay cierta confusión por parte de la bibliografía extranjera al situar el cuadro como un producto español al modo italiano (Vovelle, 1996: 106).

86 Rosenthal, 1988: 13.

87 En la España de los siglos XV y principios del XVI la Virgen lactante fue más allá de la relación entre madre e hijo, adentrándose en la lactancia de San Bernardo, en el asunto de la doble intercesión y en la distribución de la leche a los fieles, que surge de los pechos de María y ellos recogen en recipientes, según la representa Antoni Peris. 


\section{BIBLIOGRAFÍA}

Abbate, Francesco, Il Cinquecento, "Storia dell'arte nell'Italia meridionale”, 3, Roma, Donzelli, 2001.

Abbate, Francesco, “Andrea Sabatini. Trittico. 1519”, en Andrea da Salerno nel Rinascimento meridionale, cat. exp., Padula (Salerno), Certosa di San Lorenzo, 1986, pp. 140-141.

Angulo, Diego, Pintura del Renacimiento, “Ars Hispaniae”, XII, Madrid, Plus-Ultra, 1954.

Ávila, Ana, "Notas sobre el Descendimiento de Pedro Machuca", Boletín del Museo del Prado, 1987, n. ${ }^{24}$, pp. 151-153.

Ávila, Ana, "En la Capilla Real de Granada. Apuntes a algunos temas", Archivo Español de Arte, 1995, n. ${ }^{\circ} 270$, pp. 181-186.

Ávila, Ana, "Descendimiento de la cruz", en Carlos V. Las armas y las letras, cat. exp., Granada, Hospital Real, 2000, n. ${ }^{\circ} 167$.

Baldass, Ludwig, "Herzog Báró Gyüjteménye" [Die Sammlung des Baron Herzog in Budapest], Magyar Müvészet [Ungarische Kunst], 1927 (abril).

Bénézit, Emmanuel, Dictionnaire critique et documentaire des peintres, sculpteurs, dessinateurs et graveurs, París, R. Roger et F. Chernoviz, 1911-[1924].

Benito Domenech, Fernando, "Una tabla atribuida a Pedro de Machuca en la catedral de Valencia", Archivo Español de Arte Valenciano, 1985, pp. 45-46.

Bologna, Ferdinando, “Un’aggiunta a Pedro Machuca, l’iconografia di 'Gesù Bambinoportacroce' e la tomba Bonifacio di Bartolomè Ordoñez a Napoli”, Prospettiva. Scritti in ricordo di Giovanni Previtali, 1988-89 (1990), pp. 353-561.

Boubli, Lizzie, Inventaire Général des Dessins. École Espagnole. XVI'-XVIII siècle, Paris, Réunion des musées nationaux, 2002.

Burg, Tobias, Die Signatur. Formen und Funktionen vom Mittelalter bis zum 17. Jahrhundert, Berlin, Lit Verlag, 2007.

Cali, Maria, La pittura del Cinquecento, Turín, UTET, 2000.

Camón Aznar, José, La pintura española del siglo XVI, "Summa Artis", XXIV, Madrid, Espasa-Calpe, 1970.

Carlos Vy su tiempo, cat. exp., Toledo, Palacio de Santa Cruz, 1958-1959.

Catalogue of the Hungarian State Commision for the Persevation of Artistic Masterpieces, Budapest, 1944.

Catalogue des Tableaux Anciens et Modernes Composant la Collection Bourgeois Frères, Colonia, M. Dumont Schauborg, 1904.

Ceán Bermúdez, Juan Agustín, Diccionario Histórico de los más ilustres profesores de las Bellas Artes en España, Madrid, Reales Academias de Bellas Artes de San Fernando y de la Historia, 1965, III.

Chiusa, Maria Cristina, Parmigianino, Milán, Electa, 2001.

D’Aniello, Antonia, “Agostino Tesauro. Madonna delle Grazie fra Sant'Andrea e Santa Lucia post dicembre 1517”, en Andrea da Salerno nel Rinascimento meridionale, cat. exp., Padula (Salerno), Certosa di San Lorenzo, 1986, pp.

Dacos, Nicole, "Pedro Machuca en Italie", en Miscellanea Federico Zeri, Milán, Electa, 1984.

Dacos, Nicole, "Pedro Machuca", en Andrea da Salerno nel Rinascimento meridionale, cat. exp., Padula (Salerno), Certosa di San Lorenzo, 1986, pp. 248-249.

Davies, Martin, Paintings and Drawings on the Backs of National Gallery Pictures, Londres, Printed for the Trustees, 1946.

Ekserdjian, David, Parmigianino, New Haven, Yale University Press, 2006.

Exposición homenaje a D. Enrique Pérez-Comendador, cat. exp., Madrid, Instituto Egipcio de Estudios Islámicos, 1984.

Faietti, Marzia, "Pedro (Machuca), Biago (Pupini), Innocenzo (Francucci) e la Deposizione di Cristo", en “Aux Quatre Vents". A Festschrift for Bert W. Meijer, ed. de A. W. A. Boschloo, E. Grasman y G J. van der Sman, Florencia, Centro Di, 2002.

Fornari Schianchi, L.; Ferino-Pagden, S. (comisarios), Parmigianino e il manierismo europeo, cat. exp., Parma, Galleria Nazionale, 2003.

Franklin, David, L'Art de Parmesan, New Haven-Londres, Yale University Press, 2003.

Arch. esp. arte, LXXXV, 338, ABRIL-JUNIO 2012, 125-146, ISSN: 0004-0428 
Freedberg, Sydney, Parmigianino. His Works in Painting, Westport, Greenwood Press, 1971.

Giusti, Paola; Leone de Castris, Pierluigi, 'Forastieri e regnicoli'. La pittura moderna a Napoli nel primo Cinquecento, Nápoles, Electa, 1985.

Giusti, Paola; Leone de Castris, Pierluigi, Pittura del Cinquecento a Napoli. 1500-1540. Forastieri e regnicoli, Milán, Electa, 1988.

Goffen, Rona, "Signatures: Inscribing Identity in Italian Renaissance Art", Viator, 2001, n. ${ }^{\circ}$ 32, pp. 303370.

Gómez-Moreno, Manuel, Guía de Granada, s/1, 1892.

Gómez-Moreno, Manuel, "En la Capilla Real de Granada", Archivo Español de Arte y Arqueología, 1925, I, pp. $245-288$.

Gómez-Moreno, Manuel, Las águilas del renacimiento español, ed. de Agustín Bustamante, Madrid, Xarait, 1983 (1941).

Gonçalves, Flavio, “Os painéis do Purgatório e as origens das 'Alminhas' populares”, Boletim da Biblioteca Pública Municipal de Matosinhos, 1959, n. ${ }^{\circ}$ 6, pp. 1-37.

Griseri, Andreina, "Perino, Machuca, Campaña", Paragone, 1957, n. ${ }^{\circ}$ 87, pp. 13-21.

Griseri, Andreina, "Nuove schede di manierismo ibérico", Paragone, 1959, n. ${ }^{\circ} 113$, pp. 33-70.

Griswold, William M.; Wolk-Simon, Linda, Sixteenth-Century Italian Drawings in New York Collections, New York, The Metropolitan Museum of Art, 1993.

Hernández Díaz, José, El escultor Pérez-Comendador. 1900-1981 (Biografia y obra), Bilbao, Editorial La Gran Enciclopedia Vasca, 1986.

Kalby, Luigi G., "L'arrivo della maniera a Napoli e Agostino Tesauro", Bolletino di Storia dell'Arte del Centro Studi per i nuclei antichi e documenti artistici della Campania meridionale. Salerno, Avellino, Benevento, 1973, n. ${ }^{\circ} 1$.

Kalby, Luigi G., Classicismo e maniera nell'officina meridionale, Salerno, Società Editrice Salernitana, 1975.

Lafuente Ferrari, Enrique, El Prado. Del románico al Greco (1965), Madrid, Aguilar, 1978 (nueva ed. revisada por el autor).

Leone de Castris, Pierluigi, Pedro Machuca a Napoli. Due nuovi dipinti per il Museo di Capodimonte, cat. exp., Nápoles, Museo e Gallerie Nazionali di Capodimonte, 1992-1993.

Leone de Castris, Pierluigi, "Pittura e miniatura nella Napoli di Ferdinando il Catolico", en El arte en la Corte de los Reyes Cattólicos: rutas artísticas a principios de la Edad Moderna, ed. a cargo de F. Checa y B. J. García, Madrid, Fundación Carlos de Amberes, 2005 (V Seminario Internacional de Historia de la Fundación Carlos de Amberes, Madrid, 2004), pp. 75-94.

Leone de Castris, Pierluigi, "Machuca miniatore", Confronto: studi e ricerche di storia dell'arte europea, 2007, n. $^{\circ} 9$, pp. 66-81.

Llaguno y Amírola, Eugenio, Noticias de los Arquitectos y Arquitectura de España desde su restauración, Madrid, Imprenta Real, 1829.

Longhi, Roberto, "Comprimari spagnoli della maniera italiana", Paragone, 1953, n. ${ }^{\circ} 43$, pp. 3-15 ('Arte italiana e arte tedesca' con altre congiunture fra Italia ed Europa, "Opere Complete di Roberto Longhi”, IX, Florencia, Sansoni, 1979, pp. 51-61).

Longhi, Roberto, "Ancora sul Machuca", Paragone, 1969, n. ${ }^{\circ}$ 231, pp. 34-39 ('Arte italiana e arte tedesca' con altre congiunture fra Italia ed Europa, "Opere Complete di Roberto Longhi”, IX, Florencia, Sansoni, 1979, pp. 69-72).

Marías, Fernando, El largo siglo XVI. Los usos artísticos del Renacimiento español, Madrid, Taurus, 1989.

Mayer, August, La pintura española, Barcelona, Labor, 1937 (3. ${ }^{a}$ ed.).

Mayer, August, Historia de la Pintura Española, Madrid, Espasa-Calpe, 1942 (2. ${ }^{\mathrm{a}}$ ed.).

Museo del Prado. Catálogo de los cuadros, Madrid, 1942.

Museo del Prado. El Greco y la pintura española del Renacimiento, textos y fichas a cargo de Letizia Ruiz Gómez, Madrid, Museo del Prado, 2001.

Museo del Prado. Catálogo de las pinturas, Madrid, 1972.

Oertel, Robert, Frühe italienische Malerei in Altenburg, Berlín, 1961.

Pérez Comendador, Enrique (comisario), Academia Española de Bellas Artes en Roma. Primer Centenario 1873-1973, cat. exp., Roma, 1973.

Pita Andrade, José Manuel, La Pintura. De la Prehistoria a Goya, Barcelona, Corroggio, 1985. 
Pluchinotta, Alfonso Maria, Incanto e anatomie del seno, Milán, Charta, 1997.

Portús, Javier, La colección de pintura española en el Museo del Prado, Madrid, Edilupa, 2003.

Post, Chandler R., The Catalan school in the early Renaissance (Apéndice), "A History of Spanish Painting", XII (Part II), Cambridge, Mass., Harvard University Press, 1958.

Previtali, Giovanni, La pittura del Cinquecento a Napoli en el vicereame, Turín, Einaudi, 1978.

Reau, Louis, Iconographie de l'art chrétien, II (II), París, Presses Universitaires de France, 1957.

Sánchez Cantón, Francisco Javier, Fuentes Literarias para la Historia del Arte Español, I, Madrid, 1923.

Sánchez Cantón, Francisco Javier, "El Museo del Prado. Reformas y adquisiciones (1960-1962)”, Goya, 1962, n. ${ }^{\text {os }}$ 50-51, pp. 70-77.

Sánchez Cantón, Francisco Javier, Itinerario del Museo del Prado, Madrid, Editorial Peninsular, 1952.

Scaramella, Pierroberto, Le Madonne del Purgatorio: iconografia e religioni in Campania tra rinascimento e controriforma, Génova, Marietti, 1991.

Strazzullo, Franco, L'iconografia della Madonna delle Grazie tra il '400 ed il '600, Nápoles, edizioni Cancroregina, 1987.

Quintavalle, Armando Ottaviano, Il Parmigianino, Milán, Istituto Editoriale Italiano, 1948.

Rosenthal, Earl E., El palacio de Carlos Ven Granada, Madrid, Alianza, 1988.

Rubin, Patricia, "Signposts of Invention: Artists'signatures in Italian Renaissance Art", Art History, 2006, vol. 29, n. $^{\circ} 4$, pp. 563-599.

Steinberg, Leo, La sexualidad de Cristo en el arte del Renacimiento y en el olvido moderno, Barcelona, Hermann Blume, 1989.

VV.AA., "L'art de la signature", Revue de l'Art, 1974, n. ' 26, pp. 8 y ss.

Vovelle, Michel, Les âmes du purgatoire ou le travail du deuil, Paris, Gallimard, 1996.

Zambrano, Patrizia; Nelson, Jonathan Katz, Filippino Lippi, Milán, Electa, 2004.

Fecha de recepción: 24-XI-2010

Fecha de aceptación: 3-III-2011

Arch. esp. arte, LXXXV, 338, ABRIL-JUNIO 2012, 125-146, ISSN: 0004-0428 